\title{
BMJ Open Relationship between sociodemographic factors and specialty destination of UK trainee doctors: a national cohort study
}

\author{
Ben Kumwenda, ${ }^{\oplus 1}$ Jennifer Cleland, ${ }^{1}$ Gordon Prescott, ${ }^{2}$ Kim Walker, ${ }^{3}$ \\ Peter Johnston ${ }^{4}$
}

To cite: Kumwenda B, Cleland $\mathrm{J}$ Prescott G, et al. Relationship between sociodemographic factors and specialty destination of UK trainee doctors: a national cohort study. BMJ Open 2019;9:e026961. doi:10.1136/ bmjopen-2018-026961

- Prepublication history and additional material for this paper are available online. To view these files, please visit the journal online (http://dx.doi. org/10.1136/bmjopen-2018026961).

Received 5 October 2018 Revised 13 December 2018 Accepted 31 January 2019

\section{Check for updates}

(C) Author(s) (or their employer(s)) 2019. Re-use permitted under CC BY-NC. No commercial re-use. See rights and permissions. Published by BMJ.

${ }^{1}$ Centre for Healthcare Education Research and Innovation (CHERI), School of Medicine, Medical Sciences and Nutrition, University of Aberdeen, Aberdeen, UK

${ }^{2}$ Medical Statistics Team, University of Aberdeen, Aberdeen, UK

${ }^{3}$ Institute of Education for Medical and Dental Sciences, School of Medicine, Medical Sciences \& Nutrition, University of Aberdeen, UK, Centre for Healthcare Education Research and Innovation (CHERI),

Aberdeen, UK

${ }^{4} \mathrm{NHS}$, NHS Grampian and The Scotland Deanery, Aberdeen, UK

Correspondence to

Ben Kumwenda;

r01bk15@abdn.ac.uk

\section{ABSTRACT}

Objectives Many countries are driving forward policies to widen the socioeconomic profile of medical students and to train more medical students for certain specialties. However, little is known about how socioeconomic origin relates to specialty choice. Nor is there a good understanding of the relationship between academic performance and specialty choice. To address these gaps, our aim was to identify the relationship between socioeconomic background, academic performance and accepted offers into specialty training.

Design Longitudinal, cohort study using data from the UK Medical Education Database (https://www.ukmed.ac.uk/). Participants 6065 (60\% females) UK doctors who accepted offers to a specialty training (residency) post after completing the 2-year generic foundation programme (UK Foundation Programme) between 2012 and 2014. Main outcome measures $\mathrm{X}^{2}$ tests were used to examine the relationships between sociodemographic characteristics, academic ability and the dependent variable, specialty choice. Multiple data imputation was used to address the issue of missing data. Multinomial regression was employed to test the independent variables in predicting the likelihood of choosing a given specialty. Results Participants pursuing careers in more competitive specialties had significantly higher academic scores than colleagues pursuing less competitive ones. After controlling for the presence of multiple factors, trainees who came from families where no parent was educated to a degree level had statistically significant lower odds of choosing careers in medical specialties relative to general practice $(0 \mathrm{R}=0.78,95 \% \mathrm{Cl}, 0.67$ to 0.92$)$. Students who entered medical school as school leavers, compared with mature students, had odds 1.2 times higher $(95 \% \mathrm{Cl}, 1.04$ to 1.56 ) of choosing surgical specialties than general practice.

Conclusions The data indicate a direct association between trainees' sociodemographic characteristics, academic ability and career choices. The findings can be used by medical school, training boards and workforce planners to inform recruitment and retention strategies.

\section{BACKGROUND}

Matching medical workforce supply to health need is a global issue. ${ }^{1-5}$ Although the absolute number of doctors in many countries continues to grow, ${ }^{6}$ the medical workforce

\section{Strengths and limitations of this study}

This is one of the first studies in a UK setting to look at the association between socioeconomic background, academic performance and specialty (residency) choice.

- This is a nation-wide, multi-cohort study of the career decisions of doctors who successfully completed first stage of generic postgraduate training and were eligible to apply for a specialty post.

- The study used the UK Foundation Programme selection score, part of which is measured 2 years before specialty training, and is not purely a measure of academic prowess.

- We only had data on career choice of those who applied for specialty training in year 2 of the Foundation Programme F2, meaning that the sample represented approximately half of those completing the UK Foundation training each year.

is unevenly distributed geographically and some specialties are more popular than others. The precise nature of this issue differs by context, but in countries like Australia, Canada, UK and the USA, for example, there has been a reported decline of doctors who choose careers in community-based specialties, general practice / family medicine and mental health relative to hospital-based specialties. $^{478}$

Research has examined how factors such as geographical location, gender, career aspiration, work-life balance and perceived financial rewards play a crucial role in determining the career choice of healthcare workforce. ${ }^{9-15}$ Other studies have looked at the relationship between socioeconomic origin and where doctors practice. ${ }^{16}{ }^{17}$ However, very little is known about the extent to which individuals' socioeconomic origin and academic ability relate to their specialty choice.

This is important for various reasons. We know from previous research that early academic achievement is associated with socioeconomic background, and that early 
academic performance predicts performance in later years of postgraduate training. ${ }^{18} 19$ There is also evidence that different groups perform differently at medical school and during selection to postgraduate medical training. ${ }^{20}{ }^{21}$ What we do not know is the relationship between academic performance and career choices although this is likely to be an important factor in medical careers decision making given that some specialties are more competitive than others.

To date, studies examining UK doctors' career choices have tended to be mostly descriptive in nature, typically focusing on gender and ethnicity differences but neglecting other sociodemographic variables. ${ }^{122-26}$ In a recent exception to this, Santana and Chalkley found that doctors who attended privately funded (high) schools (where school is a proxy for socioeconomic status) were 1.8 and 1.4 times more likely to train in surgical or medical specialties (relative to general practice) respectively than those who attended a state (high) school. ${ }^{27}$ However, this study did not examine the relationship between performance at medical school and medical career (specialty) choice. Another recent study looked specifically at the association between demographic and educational factors and junior doctors' decisions to apply for general practice training. ${ }^{28}$ This study reported that the odds of applying to general practice training were associated with particular demographic factors (being female, non-white or secondary educated in the UK increased the odds of application) and educational factors (non-graduate entry, intercalation and above-median academic performance during medical school) all decreased the odds of applying to general practice training. ${ }^{28}$

We were interested in the associations between demographic and educational factors and junior doctors' decisions to apply for training in any specialty. Therefore, we investigated whether choice of specialty is influenced by socioeconomic background, academic ability or a combination of both. This question is timely because of recent investment and policy drivers in the UK to widen the socioeconomic profile of medical students and to train more medical students specifically to work in certain specialties, in particular general practice and psychiatry. ${ }^{29}$ However, there is not a linear relationship between number of medical students and workforce distribution. While small-scale studies have shown that there is an association between doctors from certain sociodemographic background and preference for certain specialties, ${ }^{16} 3031$ increasing the number of students in medical schools alone, without considering the effect of other factors such as specialty culture and perceived attractiveness, could lead to unintended consequences, such as training even more doctors who wish to work in urban specialist practice. Moreover, concerns about continued disadvantage in medical education and training, for students who come from non-traditional backgrounds, have been raised before. ${ }^{32}$ This leads to questions about whether specialty destination also differs on the basis of socioeconomic class or other contextual markers, including academic ability.

To address these gaps in knowledge, the aim of this study was to identify the relationship between socioeconomic background, performance at the point of selection into the first stage of generic postgraduate training in the UK (the Foundation Programme (FP) - see background to this study) and accepted offers into specialty (residency) training.

\section{METHODS}

\section{Background to this study}

Our context is the UK's postgraduate medical training pathway. UK medical students spend between 4 and 6 years at medical school before they enter foundation training, the generic 2-year training programme (the FP) which bridges the gap between finishing medical school and becoming eligible to apply for specialty (residency) training. At the end of the first year of the FP, doctors who have successfully achieved their competencies gain full registration with the UK General Medical Council (GMC), recognising progression to postgraduate medicine. Following this, the second year of the FP (F2) is the first opportunity for doctors to apply for a specialty training post.

Fewer than half of doctors who completed the FP in 2017 applied for a training post in F2 and progressed directly into specialty training. Many doctors applied for posts that were not directly aligned to specialty training programmes such as termed service posts, fellowships or went to work overseas and or in pursuit of academic or other qualifications. ${ }^{33}$ The majority of the doctors who take time out of training return within 3 years. ${ }^{33}$ However, this pattern of behaviour presents a challenge at policy level. It suggests that training policy is misaligned with the expectations and aspirations of junior doctors, and because of this, it is difficult to extrapolate the number of doctors who will move into the next phase of training simply by using the number of students in medical schools or those in foundation training. Similarly, forecasting career choices based on early career preferences made at medical school is problematic because these may change over time. ${ }^{34}$

\section{Data description}

We used linked individual-level data from the UK Medical Education Database (UKMED: https://www.ukmed.ac. $\mathrm{uk} /$ ) as the basis for this study. UKMED allows the analysis of data from a number of sources, including medical school admissions and assessment, postgraduate selection, assessment and training outcomes. ${ }^{35}$

Our cohort comprised 13731 students (43\% male, $57 \%$ female) who graduated from 33 UK medical schools between 2012 and 2014 and were eligible to apply for postgraduate training. Of these 13731 graduates, 12517 applied for allocation to the FP. A total of 1214 trainees 
applied for the Academic Foundation Programme (AFP) but were excluded from the current analysis because the AFP has a different, completely separate, selection process from the 'standard' FP. In the cohort under study, 6484 trainees (2932 males and 3552 females, $47.1 \%$ of the sample) had not applied for a specialty post at the time of the data extract. Thus, this study focuses on the 6065 trainees (60\% female) who accepted offers to level 1 (the first year of) specialty training on completion of their FP. Online supplementary file 1 shows a schematic flowchart of the data sources.

The UKMED also contains self-declared demographic data such as age, gender and ethnicity. An individual's ethnicity is grouped as either white (the majority ethnic group) or from minority ethnic groups such as asian, black or mixed race. In addition, the UKMED contains variables that relate to academic performance and socioeconomic status-with the latter used in previous research examining factors that influence educational achievement of students from different backgrounds, particularly in terms of widening participation. ${ }^{20}{ }^{36-38}$ These socioeconomic variables include: parental postcode at the time the student applied to medical school, parental occupation (derived from National Statistics Socioeconomic Classification), receipt of income support; entitlement to free school meals, Participation of Local Area (POLAR) which is an indicator of the participation of young people in higher education by geographic area, Index of Multiple Deprivation (IMD) which is an area measure of socioeconomic status routinely used in UK education and health services research, type of school (state or private) and parental education. We also included place of medical qualification in the analysis (UK country: England, Scotland, Wales and Northern Ireland).

\section{Outcome data}

In addition to the sociodemographic and academic performance data, the UKMED also includes career choice data from ORIEL, ${ }^{39}$ a centralised online system for managing specialty recruitment and career progression in medical training. Doctors who have full registration with the GMC and who have successfully completed the FP are eligible to apply for more than one specialty post anywhere in the UK via a competitive national selection process. Specialty posts are offered on the basis of ranking, and individuals can only accept one post at any given time.

We identified 56 medical training pathways in ORIEL (eg, orthopaedic surgery, general practice, renal medicine, otolaryngology). These pathways are the route to specialist registration for doctors as defined by the Royal College and Faculty curricula approved by the UK General Medical Council. ${ }^{40}$ For the purposes of analysis, we collapsed and reclassified these 56 pathways into seven categories, following advice from NHS Education Scotland (personal communication, 2017). Therefore, the outcome measure was a specialty choice in one of the following categories: Anaesthesia and Emergency Medicine; Diagnostics; General Practice; Medical Specialties;
Surgical Specialties; Mental Health; Obstetrics, Gynaecology and Medical Paediatrics. A full list of reclassification of the specialties is provided in online supplementary file 2.

The second outcome measure was the UK Foundation Programme (UKFP) selection score, a combined measure of individual student's academic performance across all years of medical school and during the selection process into the first phase of postgraduate training. The UKFP score is the sum of the Education Performance Measure (EPM) and performance on a uniform Situational Judgement Test (SJT). The EPM is worth a maximum of 50 points and comprises three parts; medical school performance (calculated in deciles, 34-43 points); additional degrees, $0-5$; and other educational achievements such as publications and presentations, 0-2 (referred to as the AEA, or additional educational achievements). The SJT is also worth up to 50 points. ${ }^{41}$ The EPM and SJT together have a maximum score of 100 points, and an applicant's score out of 100 is their UK Foundation Programme (UKFP) application score. Note that the SJT component of the UKFP application score for the graduating cohort of 2012 $(\mathrm{n}=3177)$ was used on a pilot basis and did not contribute to allocation or scoring. Finally, we looked at the association between UKFP application score and specialty choice.

\section{Statistical analyses}

We used the median and IQR to describe the UKFP selection scores across several sociodemographic factors. We used Kruskal-Wallis and Mann-Whitney U tests to compare these scores across independent groups. We used Pearson's $\chi^{2}$ tests (and Fisher's exact test where necessary) to test for associations between sociodemographic factors and specialty choice. We conducted a multinomial regression to test whether independent variables could be used to predict the likelihood of trainees choosing a given specialty in relation to general practice (the reference group). Only those variables that showed significant associations at the bivariate level and appeared not to measure overlapping constructs were entered into the regression model. For example, the variables parental occupation and parental education appear to measure broadly the same construct-socioeconomic status. Therefore, only one socioeconomic status variable-parental educationwas tested in the regression model.

In order to address a large amount of missing data in a key variable, we used regression based multiple imputation to simulate five imputed datasets, and used these to account for the missing data. Regression coefficients were obtained using non-imputed data (complete case analysis). Pooled multinomial regression estimates were also obtained as weighted averages of the estimates from these five simulated datasets. All the data analyses were completed using IBM SPSS Statistics for Windows, V.24 (IBM).

\section{Patient and public involvement}

Patients and the general public were not involved in the design of this research. Access to the data was limited to 
Table 1 The relationship between UK Foundation Programme application score and level (year) 1 specialty offers (2013 and 2014 data only)

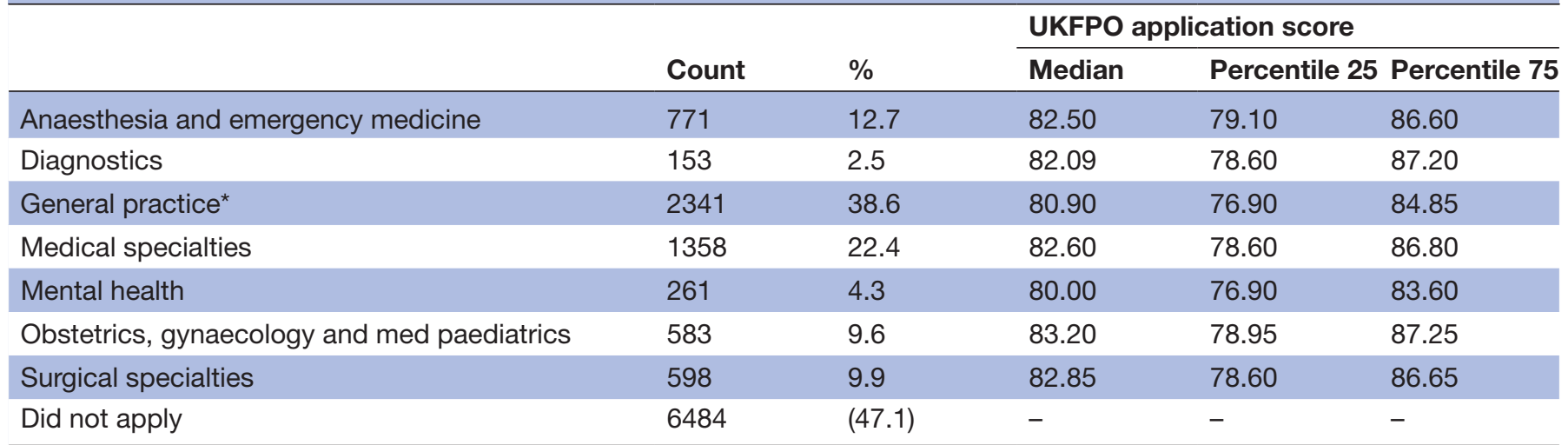

*Includes fewer than 10 trainees who applied for Public Health.

specific members of the research team via a safe haven (to ensure adherence to the highest standards of security, governance and confidentiality when storing, handling and analysing identifiable data). Ethics approval was not required because the focus of this study was a secondary analysis of anonymised data. ${ }^{35}$

\section{RESULTS}

Out of the 6065 doctors who accepted offers for a training post, the most popular choice was general practice $(\mathrm{n}=2341,38.6 \%)$, and the least popular training was mental health $(\mathrm{n}=261,4.3 \%)$.

Table 1 shows the relationship between UKFP application score and level (year) 1 specialty offers. In general, trainees who accepted offers for a post in obstetrics, gynaecology and paediatrics had the highest UKFP application scores (median=83.20, IQR=78.95-87.24) compared with those who applied for other specialities. Those applying for a mental health training position had the lowest UKFP selection scores $($ median $=80.00, \mathrm{IQR}=76.90-83.60)$.

Table 2 shows the relationship between demographic factors, specialty offers and median performance on the UKFP selection process. UKFP scores were significantly lower for men, mature students (compared with those who entered medicine directly after high school), those with non-managerial/non-professional parental occupation, no parent with a degree, those who received free school meals or income support, being from an area of low participation (POLAR) and those not of white ethnic group. However, the sizes of these statistically significant differences in median UKFP scores were small. For example, trainees who had ever received free school meals when they were in primary or secondary education (a proxy of low socioeconomic status) had significantly lower UKFP scores (median=82.4, IQR [78.5-86.4]) compared with those who never received free school meals (median=83.9, IQR [80.3-87.6]). There was no statistically significant association between school type, graduate status or UK domicile and performance on the UKFP scores.

Associations between specialty choice and sociodemographic variables were all statistically significant at $\mathrm{p}<0.001$ with the exception of the contextual variables of parental occupation $(\mathrm{p}=0.002)$, free school meals $(\mathrm{p}=0.018)$, income support $(\mathrm{p}=0.010)$ and POLAR $(\mathrm{p}=0.024)$.

There were significant differences in specialty choice by gender. Higher percentages of females than males chose careers in general practice, obstetrics, gynaecology and medical paediatrics than would be expected if all were similar. On the other hand, higher than expected percentages of males than females chose careers in surgical specialties, diagnostics, anaesthesia and emergency medicine. The highest proportion of females was observed in obstetrics, gynaecology and medical paediatrics $(78.9 \%)$, the lowest in surgical specialties $(38.0 \%)$.

Significantly higher percentages of those doctors who choose medical specialties $(74.5 \%)$ entered medical school as school leavers (rather than as graduates). In contrast, higher percentages of those who chose diagnostics $(41.8 \%)$, general practice $(38.4 \%)$ and mental health $(39.5 \%)$ were mature students. This pattern of specialty choice was also reflected in those who entered medical school as graduates (note not all mature students entering medical school are graduates).

Seventy-six per cent $(76 \%)$ of trainees had attended state-funded schools. Trainees choosing anaesthesia and emergency medicine, general practice and obstetrics, gynaecology and medical paediatrics were slightly more likely to have been to a state-funded school or college (77.8\%, $78.9 \%$ and $77.9 \%$, respectively) than those who choose diagnostics, surgical specialties or mental health.

The highest percentages of trainees with a parent/ guardian from the non-professional occupations National Statistics Socio-economic Classification II-IV (NS-SEC II-IV) were observed in mental health (15.0\%) and general practice $(12.4 \%)$. Trainees from family backgrounds where no parent was educated to a degree level 


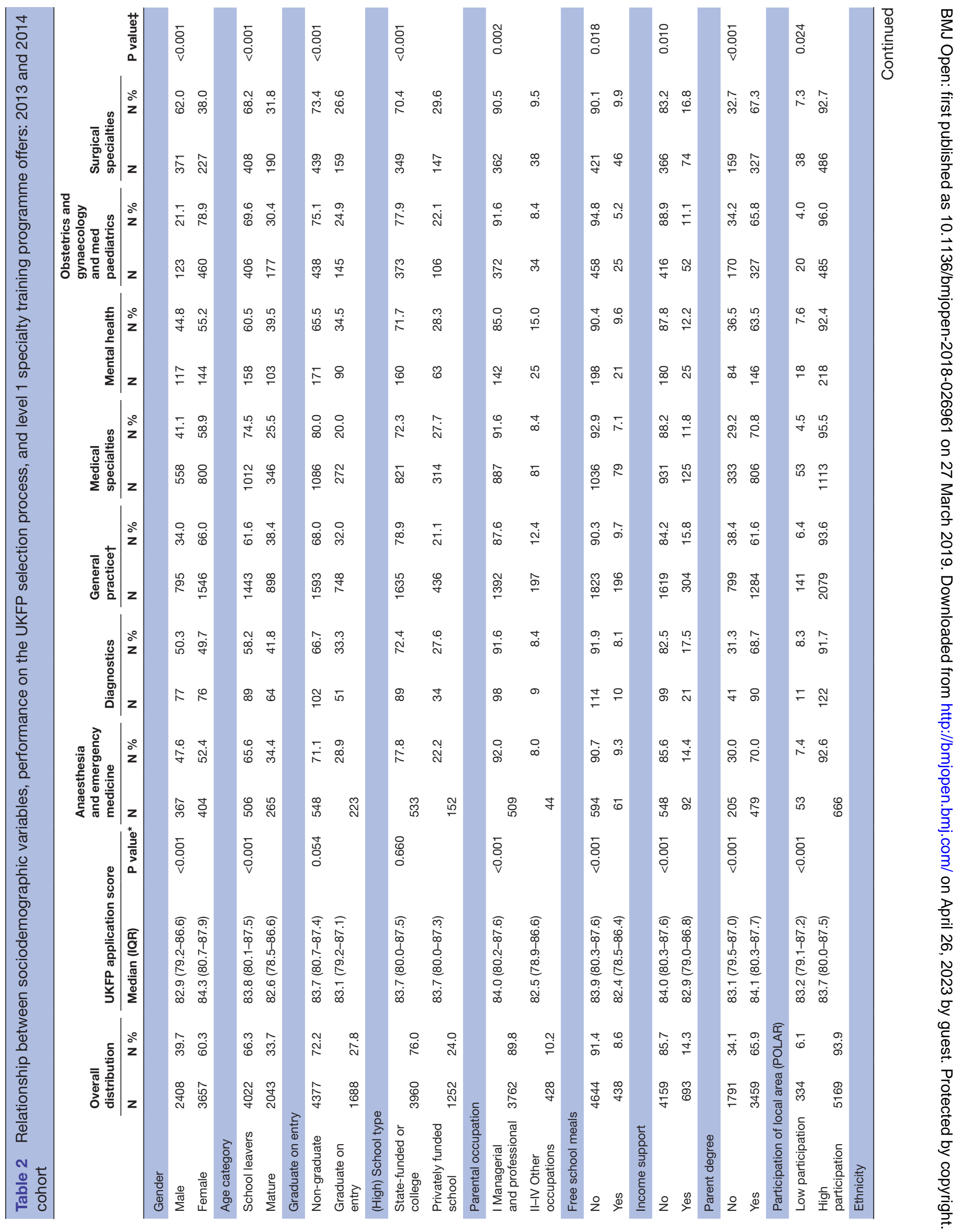




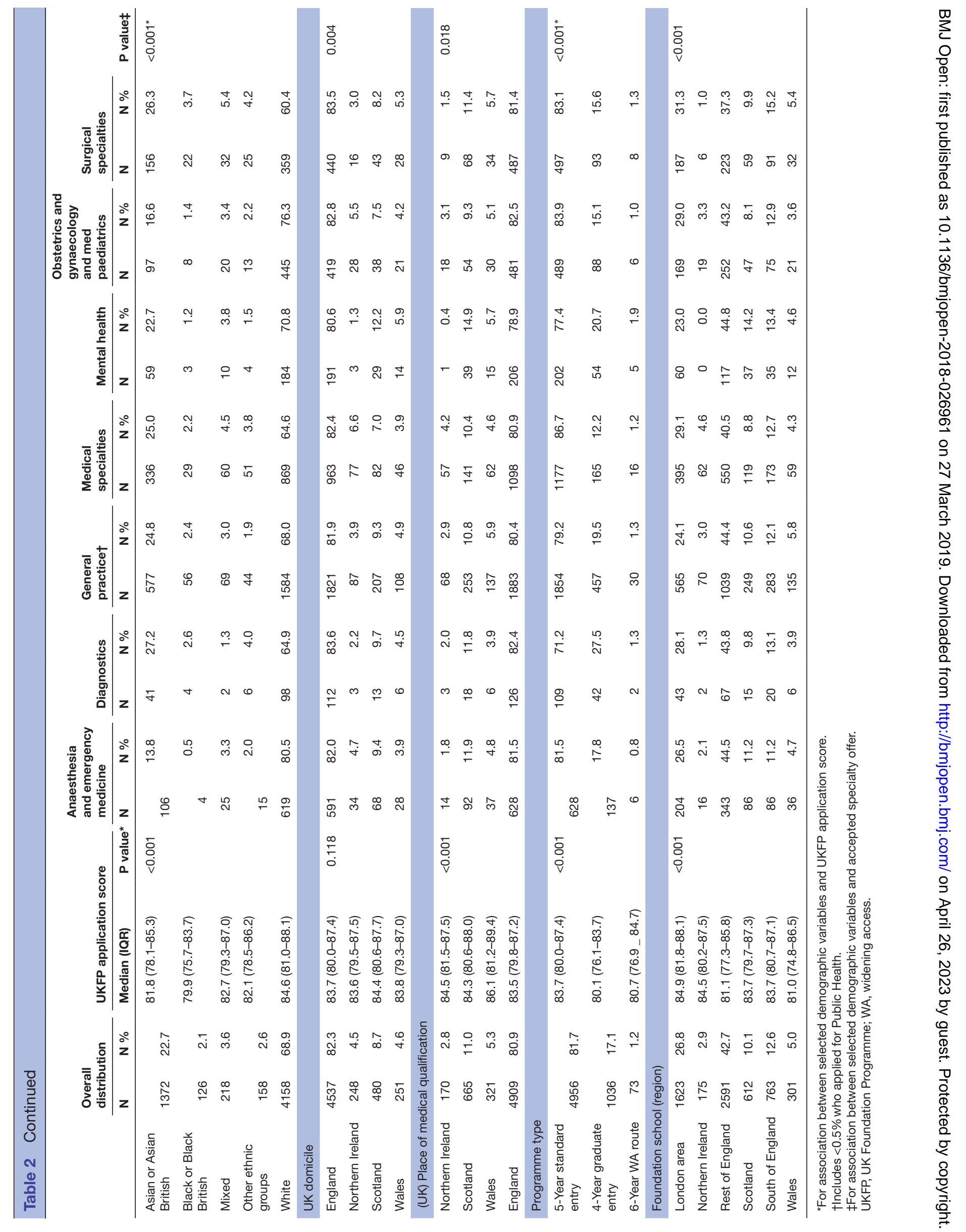


accounted for $31 \%$ of trainees. Their representation was also notably higher in those who chose mental health $(38.4 \%)$ and general practice $(36.5 \%)$.

Trainees who came from backgrounds where they had received free school meals when they were in primary or secondary education represented less than $9 \%$ of the population under study. The highest percentage of trainees whose families were, at some point, recipients of income support was observed in general practice $(15.8 \%)$, and their lowest representation was in obstetrics, gynaecology and paediatrics $(11.1 \%)$.

The association between ethnicity and specialty choice shows that the percentage of trainees of Asian background was higher than expected in diagnostics $(27.2 \%)$ and surgical specialties $(26.3 \%)$. In contrast, the percentage of white trainees was lowest in surgical specialties (60.2\%).

\section{Results of multinomial logistic regression}

We conducted a multinomial regression to predict the likelihood of trainees choosing a given specialty in relation to general practice (the largest, and thus the reference group). Of the 6065 trainees who accepted specialty training post, $3242(53.5 \%)$ had missing data for UKFP application score. table 3 shows the results of the multinomial regression models based on non-imputed (complete case analysis) and imputed data. The results (as represented by the ORs) between complete case and imputed analyses did not vary substantially in terms of direction and magnitude for any of the included sociodemographic variables. This suggested that the missing UKFP application scores did not have the effect of biasing the results.

Model 1 comprised 2823 cases for six predictor variables; gender, school type, parental education, ethnicity (reclassified into white vs black and minority ethnic [BME]), income support and UKFP application score and only complete cases. The Pearson $\chi^{2}$ goodness-of-fit test for model 1 indicated that the model was a good fit to the data, $\mathrm{p}<0.001$. The reference groups for the control variables (therefore not shown in table 3 ) were female gender, trainees who entered medical school as mature students (aged 21 and above), trainees with a parent educated to degree level, those who attended privately funded (high) school and trainees who identified their ethnicity as white. Model 2 comprised 6065 cases and had the same predictor variables as model 1 , but it was based on imputed data for UKFP application score. Model 3 was run on all cases presented in model 1 , except for the effect of UKFP application score. Therefore, the number of cases for model 3 was brought back to 6065 entries after omitting the effect of UKFP application score. ORs greater than one indicate a greater odds of trainee trainees choosing a specific specialty rather than the reference group, general practice. Similarly, ORs of less than one denote a lesser odds of trainees choosing a specialty other than the reference group.

Model 2 shows that after controlling the presence of multiple factors, including the UKFP application score, males had significantly higher odds of choosing anaesthesia and emergency medicine $(\mathrm{OR}=1.9,95 \% \mathrm{CI}$ 1.61 to 2.25 ); diagnostics ( $\mathrm{OR}=2.0,95 \% \mathrm{CI}, 1.44$ to 2.80$)$; medical specialties (OR=1.41, 95\% CI, 1.23 to 1.63$)$; mental health (OR=1.57,95\% CI, 1.27 to 2.04$)$ and surgical specialties $(\mathrm{OR}=3.31,95 \% \mathrm{CI}, 2.74$ to 4.00$)$ than general practice. However, for males the odds of choosing careers in obstetrics and gynaecology reduced by $45 \%$ $(\mathrm{OR}=0.55,95 \% \mathrm{CI}, 0.44$ to 0.67$)$, relative to females, compared with general practice. Those who entered medical school as school leavers, compared with mature students, had odds 1.2 times higher (95\% CI, 1.04 to 1.48) of choosing anaesthesia and emergency medicine, 1.7 times higher (95\% CI, 1.48 to 2.01 ) of choosing medical specialties, 1.4 times higher (95\% CI, 1.17 to 1.75$)$ of choosing obstetrics and gynaecology and 1.2 times higher (95\% CI, 1.04 to 1.56$)$ of choosing surgical specialties than general practice. Trainees who came from families where no parent had a degree, compared with those who had at least one parent with a degree, had ORs of 0.78 (95\% CI, 0.67 to 0.92 ) (22\% decrease) for choosing medical specialties relative to general practice. The odds of choosing a specialty other than general practice for trainees who attended state (high) school, compared with those who attended private (high) school, were multiplied by a factor of 0.82 (95\% CI, 0.68 to 0.98$)(18 \%$ decrease) for medical specialties; 0.66 (95\% CI, 0.49 to $0.90)$ ( $44 \%$ decrease) for mental health and $0.73(95 \%$ CI, 0.56 to 0.95 ) (27\% decrease) for surgical specialties.

The odds of trainees who identified as non-white, compared with white, to choose a specialty other than general practice were multiplied by a factor of $0.51(95 \%$ CI, 0.42 to 0.63 ) (49\% decrease) for anaesthesia and emergency medicine and 0.68 (95\% CI, 0.55 to 0.85 ) (32\% decrease) in obstetrics and gynaecology. However, those from BME, compared with white trainees, had odds 1.4 times higher (95\% CI, 1.10 to 1.65 ) of choosing surgical specialties compared with general practice. Model 3 shows that when all the variables were incorporated into the model, except for the effect of UKFP application score, the association between ethnicity and career choice in anaesthesia and emergency medicine (OR 0.46, $95 \%$ CI 0.37 to 0.58$)$, and mental health $(0.68,95 \%$ CI 0.48 to 0.95$)$ remained statistically significant.

\section{DISCUSSION}

To the best of our knowledge, this is one of the few studies in a UK setting to look at the association between socioeconomic background, performance and specialty choice in doctors making their specialty (residency) career decisions. Our analysis indicates that socioeconomic background and, to a lesser extent, performance on the Foundation Programme selection measures are important factors in predicting career choices and pathways. We found that trainees who pursued careers in more competitive specialties had significantly higher Foundation selection scores than colleagues who pursued less competitive ones. We also found that doctors who entered medical school as mature 


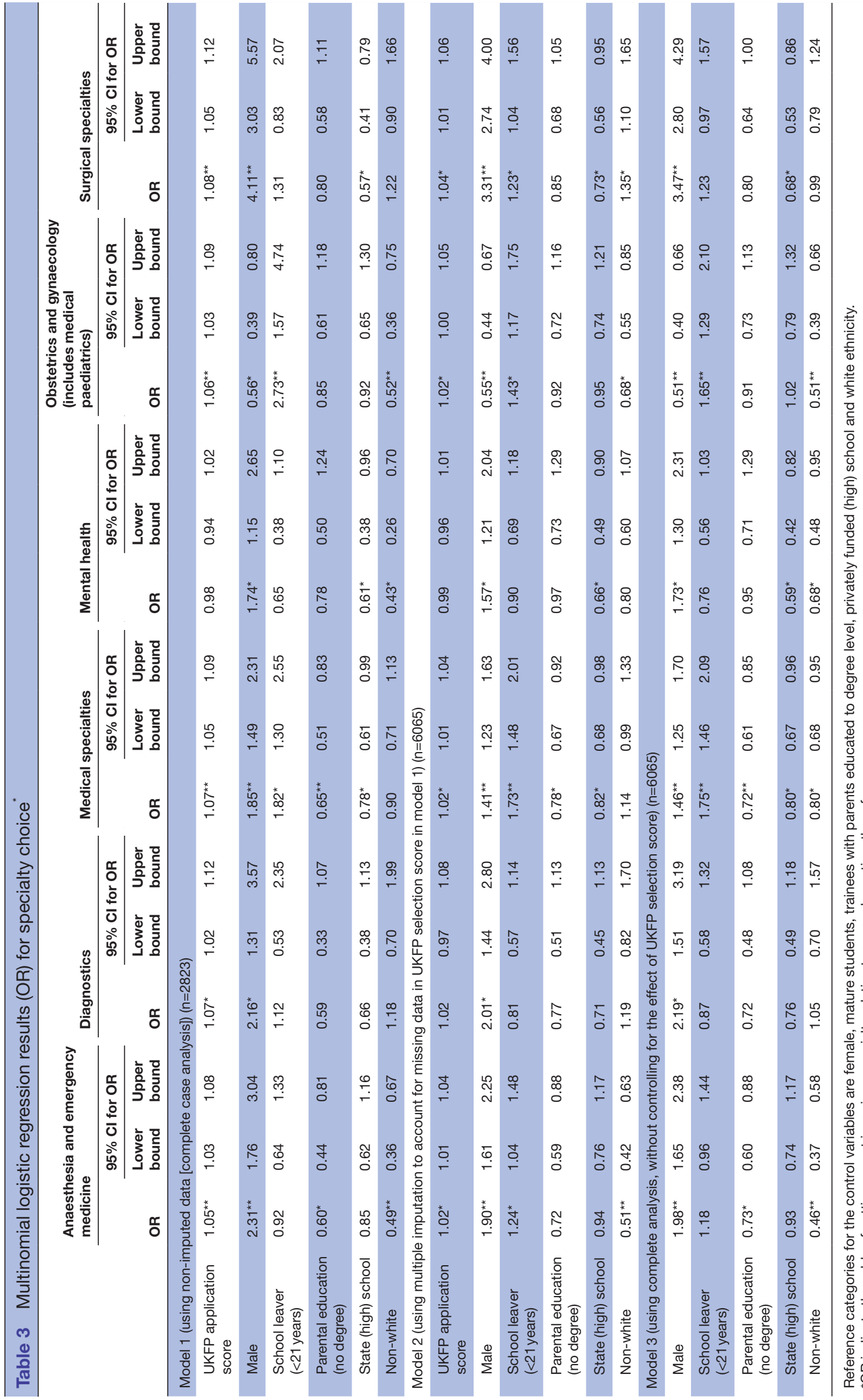


students and those from lower socioeconomic backgrounds had significantly lower performance on this measure, and were more likely to choose careers in general practice and mental health relative to other specialties. This latter finding aligns with that of Gale $e t a l$, who found that doctors who entered medical school as graduate applicants, compared with non-graduates, were more likely to apply for general practice training. ${ }^{28}$

General practice has struggled to fill its training places over the last few years. ${ }^{42}$ This recruitment issue is coupled with an ageing general practice workforce and fewer general practice trainees wishing to work full-time after full qualification. ${ }^{43} 44$ Our multivariate analysis suggests that increasing the number of mature students and students from lower socioeconomic (non-traditional) backgrounds could help general practice recruitment.

Our results could be interpreted as students who come from non-traditional backgrounds tending to perform less well, have significantly lower Foundation Programme selection scores (as evidenced by our findings), and not applying for certain specialties as they do not believe they can compete for a training post with those who performed better on the UKFP. ${ }^{32}$ However, the weaker performance of non-traditional students on Foundation Programme selection may be due to financial rather than ability differences. As indicated in the methods section, the UKFP application score comprises other parts that are not solely a measure of academic performance. For example, medical students from less affluent backgrounds may opt out of intercalated degrees or medical electives abroad because of cost, despite these being factors that contribute towards attainment at medical school and score/ranking on the UKFP. ${ }^{45-47}$ The influence of additional educational attainments on specialty post offers requires further examination as does exploring personal reasons for making specialty choices.

These patterns may also indicate that 'disadvantage continues' in that those doctors who come from non-traditional backgrounds are less likely to obtain training posts in what are perceived as the most competitive specialties. ${ }^{48} 49$ Our study corroborates other non-UK studies and anecdotal evidence highlighting the challenges faced by doctors in terms of pursuing certain medical careers. ${ }^{50}$ However, is this finding due to lack of confidence, feeling one does not fit with a particular specialty and/or is it related to those from non-traditional backgrounds performing less well early in their careers (ie, at medical school and in the selection process for the UKFP) ? ${ }^{51-53}$ Further qualitative research is required to explore the factors that attract or deter doctors from widening access backgrounds to apply for certain specialties.

Finally, general practice training is much shorter than many other specialties and general practice trainees tend to work in one place rather than rotating around (often geographically dispersed) hospitals. This may mean fewer financial demands on trainees than other pathways ${ }^{54-56}$ and thus may appeal to more mature trainees/residents who are likely to have greater financial and domestic commitments than younger ones. ${ }^{57} 58 \mathrm{~A}$ recent report looking at how doctors progress through postgraduate training also highlighted how mature and graduate entry trainees are concerned with getting through training as quickly as possible. ${ }^{59}$ Similarly, this urgency to get through training quickly may also appeal to those from lower socioeconomic backgrounds who may be more concerned with paying back their student loan than those from more affluent groups. ${ }^{6061}$

The differences we noted in gender and ethnicity are consistent with the wider literature. For example, our results resonates with other studies that show how doctors from BME groups perform less well in academic and recruitment outcomes compared with white doctors..$^{192-64}$ However, after controlling for the effect of UKFP selection score, the association between ethnicity and specialty choice was no longer significant for most specialties, except in anaesthesia and emergency medicine (49\% decrease) and obstetrics and gynaecology ( $32 \%$ decrease). This echoes findings from a previous study by Woolf $e t$ al which reported how negative relationships between senior doctors and trainees discouraged some of the BME trainees from pursuing careers in anaesthetics. ${ }^{63}$ Our data also indicate that BME trainees have increased odds of choosing careers in surgical specialties compared with general practice. This might be dependent on the other confounding factors that have not been explained by the regression model. These factors may include cultural and family influence,${ }^{6566}$ trainees' perception of the specialty, experience during medical school, influence of role models or mentors and personal career needs. ${ }^{26}$ This also requires further qualitative research to explore the social and cultural capital ${ }^{67}$ that non-traditional students bring with them into medical education and training.

The strength of this study is that it is one of the first to use the UKMED to examine the associations between sociodemographic factors, academic ability and the full range of specialty career choices. The UKMED enabled a nationwide, multi-specialty and multi-cohort analysis. However, we must also acknowledge some potential limitations of the study. First, in our previous research on selection into postgraduate (F2) training we reported how some of the contextual markers included in the analysis overlap, particularly socioeconomic class, ethnicity and place of medical qualification. ${ }^{32}$ We believe that these have a similar effect on specialty choice given the links between place, poverty and ethnicity in the UK. ${ }^{69}$ Second, we used the UKFP selection score as an indicator of performance. As outlined earlier, this score comprises an individual's performance at medical school plus outstanding academic features such as an additional degree or publications, and an SJT (the other $50 \%$ ). In short, it is an indicator, measured 2 years before specialty training and is not purely a measure of academic prowess. However, we used this for several reasons. First, the UKFP competency outcome measures which assess progression during the UKFP do not differentiate at the level we needed for meaningful analysis. Alternative outcome measures may have included specialty interview score or ranking during the specialty selection process, but 
UKMED did not hold this data at the time of the study. Moreover, specialty selection scores are not directly comparable because different specialties use different selection processes. In short, we used the best measure available at the time. As UKMED expands, future studies may wish to rerun this study with alternative outcome measures such as those mentioned above.

The nature of specialty selection in the UK is that eligible doctors can apply for many different specialties and different posts. We did not have information on specialty applications, only on offers (ie, where an individual had been successful in his or her application) because the data extract used in the analysis contained phase 1 of the UKMED data. ${ }^{35}$ Our sample represented approximately half of those completing the UKFP in each year group because we only had data on specialty choice from those who applied for specialty training in F2. We know that work has recently been commissioned to explore if those who apply for a training post in F2 are different (in terms of sociodemographics) to those who delay application in order to take time out of training (eg, work overseas for a period of time, take a service or an academic post). This forthcoming analysis will show if our sample is representative of the wider group. We could have included other measures of previous academic performance in the model. However, most of the other currently available measures are associated with selection into medical school and/or are not used in any later selection decisions. It may have been useful to split the UKFP selection score into its component parts (EPM, AEA, SJT) and compare each of these separately. Our reason for not doing so is that in practice it is the total score that is used in selection decision, i.e. this is the measure used to allocate postgraduate programmes and from that jobs. However, examining these specific associations may be a fruitful area for further research given that the SJT and EPM are considered to measure different factors. ${ }^{70}$ Further studies may also wish to look at specialty applications and offers as this will provide further insight into the career preferences of junior doctors from different socioeconomic backgrounds.

In conclusion, this study contributes to the evidence that there is a direct association between socioeconomic background, academic ability and career choices. This information can be used by medical school, those organisations with responsibility for medical training and workforce planners to inform selection, recruitment and retention strategies. Finally, more research is needed to examine the postgraduate training environment and workforce distribution to ensure that social accountability and fairness are upheld at all levels of training.

Acknowledgements We are grateful to UKMED for releasing the data for this project. We also are grateful to the following for their support of the application to UKMED for this and other research projects: Dr Sally Curtis (University of Southampton, UK), Dr Sandra Nicholson (Barts and The London School of Medicine and Dentistry, UK). We thank Daniel Smith and Andy Knapton of the General Medical Council of the UK for their support for the application and throughout the project, particularly regarding data linkage and troubleshooting.
Contributors JC led the funding bid which was reviewed by KW, BK and PJ. KW and PJ advised on the nature of the data. BK managed the data, carried out the data analysis under the supervision of GP and JC, and wrote the first manuscript. GP advised on all the statistical analysis. JC guided the first draft of the Introduction and Discussion sections of this paper. BK wrote the Methods and Results sections. $\mathrm{JC}$ edited the drafts. All authors reviewed and agreed on the final draft of the paper.

Funding A small grant from UKCAT Research Panel was used to cover the cost of publishing this article.

Competing interests This study is part of Ben Kumwenda's doctoral programme of research funded by the UKCAT Research Panel, of which JC is a member. KW is the Special Advisor (Recruitment) for the UK's Foundation Programme (UKFPO).

Patient consent for publication Not required.

Provenance and peer review Not commissioned; externally peer reviewed.

Data sharing statement UK Medical Education Database (“UKMED”) UKMEDP 026 extract generated on 12/08/2016. Approved for publication on 27/03/2017. UKMED bears no responsibility for data analysis or interpretation. The dataset is held in safe haven and only members of the research, BK, GP and JC had access to the data. The data includes information derived from that collected by the Higher Education Statistics Agency Limited ("HESA") and provided to the GMC ("HESA Data"). Source: HESA Student Record 2007/2008 and 2008/2009 Copyright Higher Education Statistics Agency Limited. The Higher Education Statistics Agency Limited makes no warranty as to the accuracy of the HESA Data, cannot accept responsibility for any inferences or conclusions derived by third parties from data or other information supplied by it.

Open access This is an open access article distributed in accordance with the Creative Commons Attribution Non Commercial (CC BY-NC 4.0) license, which permits others to distribute, remix, adapt, build upon this work non-commercially, and license their derivative works on different terms, provided the original work is properly cited, appropriate credit is given, any changes made indicated, and the use is non-commercial. See: http://creativecommons.org/licenses/by-nc/4.0/.

\section{REFERENCES}

1. Zurn P, Dal Poz MR, Stilwell B, et al. Imbalance in the health workforce. Hum Resour Health 2004;2:13.

2. Simoens S, Hurst S. The Supply of physician services in oecd countries. 2006 http://www.oecd.org/health/health-systems/ 35987490.pdf.

3. Dussault G, Franceschini MC. Not enough there, too many here: understanding geographical imbalances in the distribution of the health workforce. Hum Resour Health 2006;4:4-12.

4. Gorman D, Poole P, Scott SJ. On the maldistribution of the medical workforce. Intern Med J 2007;37:669-71.

5. Gorman D. Matching the production of doctors with national needs. Med Educ 2018;52:103-13.

6. Organisation for Economic Co-operation and Development (OECD). "Doctors (Overall number)", in Health at a Glance. 2017 https://doi. org/10.1787/health_glance-2017-52-en.

7. Jeffe DB, Whelan AJ, Andriole DA. Primary care specialty choices of United States medical graduates, 1997-2006. Acad Med 2010;85:947-58.

8. Royal Collage General Practitioners (RCGP). Primary Care Workforce Survey highlights need for strong action to tackle GP workforce shortage. 2018 http://www.rcgp.org.uk/about-us/news/2018/march/ primary-care-workforce-survey-highlights-need-for-strong-action-totackle-gp-workforce-shortage.aspx (Accessed Jul 2018).

9. Edwards C, Lambert TW, Goldacre MJ, et al. Early medical career choices and eventual careers. Med Educ 1997;31:237-42.

10. Owen JA, Hayden GF, Bowman RC. Influence of places of birth, medical education, and residency training on the eventual practice locations of family physicians: recent experience in Virginia. South Med J 2005;98:674-5.

11. Goldacre M, Davidson J, Maisonneuve J, et al. Geographical movement of doctors from education to training and eventual career post: UK cohort studies. J R Soc Med 2013;106:96-104.

12. Smith F, Lambert TW, Goldacre MJ. Factors influencing junior doctors' choices of future specialty: trends over time and demographics based on results from UK national surveys. J $R$ Soc Med 2015;108:396-405.

13. Lambert TW, Smith F, Goldacre MJ. Career specialty choices of UK medical graduates of 2015 compared with earlier cohorts: questionnaire surveys. Postgrad Med J 2018;94:191-7. 
14. Scanlan GM, Cleland J, Johnston P, et al. What factors are critical to attracting NHS foundation doctors into specialty or core training? A discrete choice experiment. BMJ Open 2018;8:e019911.

15. Sivey P, Scott A, Witt J, et al. Junior doctors' preferences for specialty choice. $J$ Health Econ 2012;31:813-23.

16. Dowell J, Norbury M, Steven K, et al. Widening access to medicine may improve general practitioner recruitment in deprived and rural communities: survey of GP origins and current place of work. BMC Med Educ 2015;15:165.

17. Puddey IB, Playford DE, Mercer A. Impact of medical student origins on the likelihood of ultimately practicing in areas of low vs high socio-economic status. BMC Med Educ 2017;17:13.

18. McManus IC, Woolf K, Dacre J, et al. The academic backbone: longitudinal continuities in educational achievement from secondary school and medical school to MRCP(UK) and the specialist register in UK medical students and doctors. BMC Med 2013;11:27.

19. Scrimgeour D, Cleland J, Lee AJ, et al. Predictors of success in the Intercollegiate Membership of the Royal College of Surgeons (MRCS) examination. Ann R Coll Surg Engl 2018;100:424-7.

20. McManus IC, Dewberry C, Nicholson S, et al. The UKCAT-12 study: educational attainment, aptitude test performance, demographic and socio-economic contextual factors as predictors of first year outcome in a cross-sectional collaborative study of 12 UK medical schools. BMC Med 2013;11:244.

21. Kumwenda B, Cleland JA, Walker K, et al. The relationship between school type and academic performance at medical school: a national, multi-cohort study. BMJ Open 2017;7:e016291.

22. Goldacre MJ, Turner G, Lambert TW. Variation by medical school in career choices of UK graduates of 1999 and 2000. Med Educ 2004;38:249-58.

23. Lambert TW, Goldacre MJ, Turner G. Career choices of United Kingdom medical graduates of 2002: questionnaire survey. Med Educ 2006;40:514-21.

24. Taylor KS, Lambert TW, Goldacre MJ. Career progression and destinations, comparing men and women in the NHS: postal questionnaire surveys. BMJ 2009;338:b1735.

25. Goldacre MJ, Laxton L, Lambert TW. Medical graduates' early career choices of specialty and their eventual specialty destinations: UK prospective cohort studies. BMJ 2010;341:c3199.

26. Querido SJ, Vergouw D, Wigersma L, et al. Dynamics of career choice among students in undergraduate medical courses. A BEME systematic review: BEME guide No. 33. Med Teach 2016;38:18-29.

27. Rodriguez Santana I, Chalkley M. Getting the right balance? A mixed logit analysis of the relationship between UK training doctors' characteristics and their specialties using the 2013 National Training Survey. BMJ Open 2017;7:9.

28. Gale TCE, Lambe PJ, Roberts MJ. Factors associated with junior doctors' decisions to apply for general practice training programmes in the UK: secondary analysis of data from the UKMED project. BMC Med 2017;15:220.

29. Department of Health \& Social Care. A mandate from the government to health education England: Crown Office, 2018.

30. Pamies RJ, Lawrence LE, Helm EG, et al. The effects of certain student and institutional characteristics on minority medical student specialty choice. J Natl Med Assoc 1994;86:136-40.

31. Senf JH, Campos-Outcalt D, Kutob R. Factors related to the choice of family medicine: a reassessment and literature review. J Am Board Fam Pract 2003;16:502-12.

32. Kumwenda B, Cleland JA, Prescott GJ, et al. Relationship between sociodemographic factors and selection into UK postgraduate medical training programmes: a national cohort study. BMJ Open 2018;8:e021329.

33. General Medical Council. Training pathways: analysis of the transition from the foundation programme to the next stage of training. Manchester: GMC, 2017.

34. Cleland J, Johnston PW, French FH, et al. Associations between medical school and career preferences in Year 1 medical students in Scotland. Med Educ 2012;46:473-84.

35. Dowell J, Cleland J, Fitzpatrick S, et al. The UK medical education database (UKMED) what is it? Why and how might you use it? BMC Med Educ 2018;18:6.

36. Higher Education Funding Council for England. Widening participation and fair access research strategy consultation document. Bristol: Higher Education Funding Council for England, 2004.

37. Mathers J, Sitch A, Marsh JL, et al. Widening access to medical education for under-represented socioeconomic groups: population based cross sectional analysis of UK data, 2002-6. BMJ 2011;342:d918.

38. Higher Education Funding Council for England. Young participation in higher education. Bristol: Research report, 2015.
39. NHS. Oriel. https://www.oriel.nhs.uk/Web/Account/LandingPage.

40. General Medical Council. Royal college curricula. $2018 \mathrm{https}: / / w w w$. gmc-uk.org/education/standards-guidance-and-curricula/curricula\# approved_curricula.

41. UK Foundation Programme. Applicants' handbook UKFPO, 2017. 2018 http://www.foundationprogramme.nhs.uk/pages/home.

42. The Health Foundation. Staffing Matters; Funding Counts - Pressure Point: GP recruitment and retentionat. 2016 https://www.health.org. uk/sites/health/files/SMFCGPRetention.pdf.

43. British Medical Association. Struggle to fill GP vacancies in Scotland 2018 https://www.bma.org.uk/news/2015/march/struggle-to-fill-gpvacancies-in-scotland.

44. British Medical Association. General practice in the UK- background briefing. $2017 \mathrm{https} / / / \mathrm{www}$. bma.org.uk/-/media/files/pdfs/news\% 20views\%20analysis/press\%20briefings/general-practice.pdf?la=en (Accessed June 2018).

45. Nicholson JA, Cleland J, Lemon J, et al. Why medical students choose not to carry out an intercalated BSc: a questionnaire study. BMC Med Educ 2010;10:6.

46. Mahesan N, Crichton S, Sewell H, et al. The effect of an intercalated BSc on subsequent academic performance. BMC Med Educ 2011;11:9.

47. Lumb A, Murdoch-Eaton D. Electives in undergraduate medical education: AMEE Guide No. 88. Med Teach 2014;36:557-72.

48. Creed PA, Searle J, Rogers ME. Medical specialty prestige and lifestyle preferences for medical students. Soc Sci Med 2010;71:1084-8.

49. Lepièce $B$, Reynaert $C$, van Meerbeeck $P$, et al. Social dominance theory and medical specialty choice. Adv Health Sci Educ Theory Pract 2016;21:79-92.

50. Kodadek LM, Kapadia MR, Changoor NR, et al. Educating the surgeon-scientist: a qualitative study evaluating challenges and barriers toward becoming an academically successful surgeon. Surgery 2016;160:1456-65.

51. Riley LE. Ensuring a diverse physician workforce: progress but more to be done. JAMA Intern Med 2015;175:1708-9.

52. Skinner R. Becoming a trauma surgeon: how race impacted my journey. critical research on sexism and racism in stem fields. Igi Global: Hersey, 2016:222-7.

53. Gottfredson LS. Circumscription and compromise: a developmental theory of occupational aspirations. J Couns Psychol 1981;28:545-79.

54. Academy of Medical Royal Colleges. Mandatory training costs 2017. 2017 http://www.aomrc.org.uk/wp-content/uploads/2017/10/Cost of_training_301017-rev1.pdf.

55. Stroman L, Weil S, Butler K, et al. The cost of a number: can you afford to become a surgeon? The Bulletin of the Royal College of Surgeons of England 2015;97:107-11.

56. O'Callaghan J, Mohan HM, Sharrock A, et al. Cross-sectional study of the financial cost of training to the surgical trainee in the UK and Ireland. BMJ Open 2017;7:7:e018086.

57. Grayson MS, Newton DA, Thompson LF. Payback time: the associations of debt and income with medical student career choice. Med Educ 2012;46:983-91.

58. Pyne Y, Ben-Shlomo Y. Older doctors and progression through specialty training in the UK: a cohort analysis of General Medical Council data. BMJ Open 2015;5:e005658.

59. General Medical Council. Training pathways 2: why do doctors take breaks from their training. Manchester: GMC, 2018.

60. Callender C, Jackson J. Does the Fear of Debt Deter Students from Higher Education? J Soc Policy 2005;34:509-40.

61. Lc EC. The Intersection of Student Loans and Social Class: Exploring Borrowers' Journeys into Debt and Repayment. Youn TIK, Paradoxes of the democratization of higher education. Bingley: Emerald Group Publishing Ltd, 2017:1-67.

62. General Medical Council. The state of medical education and practice in the UK: 2015. 2015 https://www.gmc-uk.org/-/media/ documents/somep-2015_pdf-63501874.pdf.

63. Woolf K, Rich A, Viney R, et al. Perceived causes of differential attainment in UK postgraduate medical training: a national qualitative study. BMJ Open 2016;6:9:e013429.

64. General Medical Council. Ethnic minority and non-UK doctors are more likely to fail exams, GMC data show. BMJ $2018 \mathrm{https} / / \mathrm{www}$. bmj.com/content/354/bmj.i4100.full.

65. Shah B, Dwyer C, Modood T. Explaining educational achievement and career aspirations among young british pakistanis: mobilizing 'ethnic capital'? Sociology 2010;44:1109-27.

66. Dwyer C, Modood T, Sanghera G, et al. Educational Achievement and Career Aspiration for Young British Pakistanis. In: Modood T, Salt J, Global migration, ethnicity and britishness. Palgrave: Basingstoke, 2011:177-204. 
67. Bourdieu P. What makes a social class? On the theoretical and practical existence of groups. Berkeley Journal of Sociology 1987;32:1-17.

68. Gillborn D, Safia Mirza H. Mapping race mapping, class and gender: a synthesis of research evidence. London: Office for Standards in Education, 2000.
69. Garner S, Poverty BG. Ethnicity and place. The Joseph Rowntree Foundation (JRF: York, 2011.

70. Smith DT, Tiffin PA. Evaluating the validity of the selection measures used for the UK's foundation medical training programme: a national cohort study. BMJ Open 2018:8. 